\title{
Estudo da regeneração esplênica autóloga e heterotópica em ratos $^{1}$
}

\author{
Antologus and heterotopic splenic regeneration in rats
}

\begin{abstract}
José Carlos Lacerda de Souza², Emilio Athiê ${ }^{3}$, Carlos Marigo ${ }^{4}$, Fares Rahal ${ }^{5}$, Djalma José Fagundes ${ }^{6}$
1. Resumo de Tese de Mestrado apresentada no Programa de Pós-Graduação em Cirurgia da Faculdade de Medicina da Santa Casa de São Paulo. Atualizado e ampliado no Programa de Pós-graduação em Cirurgia e Experimentação da Universidade Federal de São Paulo.

2. Mestre em Cirurgia pelo Programa de Pós-Graduação em Cirurgia da Faculdade de Medicina da Santa Casa de São Paulo. Professor Adjunto do Departamento de Clínica Cirúrgica, Disciplina Cirurgia do Aparelho Digestivo da Universidade Estadual de Londrina.

3. Professor Titular da Disciplina de Cirurgia do Aparelho Digestivo, da Faculdade de Ciências Médicas da Santa Casa de São Paulo.

4. Professor Adjunto da Disciplina de Anatomia Patológica da Faculdade de Ciências Médicas da Santa Casa de São Paulo

5. Professor Livre Docente da Disciplina de Cirurgia do Aparelho Digestivo da Faculdade de Ciências Médicas da Santa Casa de São Paulo.

6. Professor Adjunto e Coordenador do Programa de Pós-Graduação de Cirurgia e Experimentação da UNIFESP - EPM
\end{abstract}

\begin{abstract}
RESUMO
Objetivo: estudar a regeneração esplênica dos fragmentos de baço autólogos e heterotópicos implantados na cavidade peritoneal e na tela subcutânea em ratos e comparar os seus aspectos histológicos e citológicos com baço normal. Métodos: 44 ratos Wistar foram submetidos a esplenectomia e receberam fragmentos de auto-implante: GA = na tela subcutânea (n=22) e GB na cavidade peritoneal $(n=22)$. GAI $(n=11)$ e GAII $(n=11)$ receberam implante de fragmento único. GBIII $(n=11)$ e GBIV $(n=11)$ receberam implantes de quatro fragmentos. O baço remanescente foi usado como controle. Após 5 semanas de foram submetidos à eutanásia e foram investigados os aspectos macroscópicos e microscópicos (histológicos e citológicos) dos fragmentos nos seus locais de implante. Os resultados foram submetidos a testes estatísticos não paramétricos $(\mathrm{p}>0,05)$. Resultados: Não houve diferença estatística significante entre o grupo que recebeu implante na tela subcutânea $(n=22)$ e o grupo da cavidade peritoneal $(n=22)$. Quanto à presença ou ausência de tecidos esplênicos regenerados ( $\mathrm{p}=0,182)$, também não apresentou diferença com significância estatística. Os estudos histológicos e citológicos do tecido regenerado não evidenciaram diferenças em relação ao grupo controle. Conclusão: A regeneração do tecido esplênico autólogo e heterotópico em ratos ocorre nas mesmas proporções tanto na tela subcutânea como na cavidade peritoneal. Os aspectos histológicos e citológicos são semelhantes aos do baço normal.
\end{abstract}

Descritores - Baço, Transplante esplênico, Esplenose.

\begin{abstract}
Purpose: verify the cytological and histological aspects of the regeneration of fragments of autologous and heterotopic spleen implanted in peritoneal cavity and subcutaneous screen in Wistar albino rats. Methods: forty four Wistar rats were assigned to one of two groups $A(n=22)$ and $B(n=22)$, which received their implants in subcutaneous screen and peritoneal cavity, respectively, under anesthesia. Those groups were redistributed in two other subgroups A1 (n=11) and B1(n=11), which received one and four splenic fragments in the areas of study. The remaining spleen was guided for cytological and histological processing, and was used as a control group. After five weeks, they were submitted to euthanasia, and peritoneal cavity opening took place as well as subcutaneous screen was taken off in order to search for regenerated splenic tissue. Cytological and histological assessment in the regenerated splenic tissue was performed, and the results were compared to the control group. Statistical analysis no parametric tests $(p=>0,05)$ were used for. Results: there were no statistically significant differences in relation to regenerated splenic tissue in subcutaneous screen $(n=22)$ and the peritoneal cavity $(n=22)$. In relation between presence and absence of regeneration, they're no statistically significant differences $(\mathrm{p}=0,182)$. Cytological and histological assessment did not show any statistically significant difference in relation to the control group. Conclusion: regeneration of autologous and heterotopic splenic tissue in mice is viable, and occurs frequently. Cytological and histological aspects are similar to normal spleen.
\end{abstract}

Key words: Spleen, Transplant, Splenosis, Wistar rats.

\section{Introdução}

O baço desempenha função relevante sobre a imunidade e os elementos figurados do sangue, tanto da série vermelha como da branca. Protege o organismo nas queimaduras térmicas por meio do fator esplênico lipoidal e diminui a predisposição à embolia microvascular pulmonar ${ }^{1,2}$. A esplenectomia foi muito difundida e obteve grande aceitação, principalmente em relação ao trauma do baço, pela facilidade técnica e por coibir efetivamente a hemorragia. Durante mais da metade do século XX, a esplenectomia foi a principal indicação em caso de trauma 
de baço. Acreditava-se que a função deste não era importante e que a asplenia não causava nenhuma conseqüência no longo prazo $^{3,4}$. À partir de 1919 começou a se perceber que a esplenectomia aumentava a susceptibilidade a infecções ${ }^{5}$. Somente em 1952, porém, esse fato alcançou repercussão quando foi relatada a ocorrência de infecção fulminante pós-esplenectomia ${ }^{6}$. Seguiram-se vários relatos clínicos de infecção grave pósesplenectomia e de trabalhos experimentais que demonstravam maior susceptibilidade de animais asplênicos à infecção ${ }^{1-7}$. Observações clínicas e experimentais têm demonstrado que, após a esplenectomia, ocorrem alterações na imunidade, representadas pela diminuição da IgM sérica, pela redução da capacidade de opsonização do soro e pela incapacidade e cessação da produção de tuftisina (tetrapeptídeo facilitador da fagocitose bacteriana) ${ }^{8,9,10} \mathrm{e}$ que predispõem a riscos de infecção cuja incidência varia de 0,3 a $4,25 \%{ }^{7,8}$, com taxa de mortalidade de até $50 \%^{8}$. A infecção grave após a esplenectomia não é uma contraindicação absoluta. A indicação necessita ser precisa e bemfundamentada e com benefícios que superem os riscos ${ }^{1-11}$.

O melhor conhecimento das conseqüências da esplenectomia acarretou mudanças na conduta cirúrgica em relação ao tecido esplênico voltada à sua conservação, como esplenectomias parciais, tamponamentos, aplicação tópica de hemostáticos e embolização ${ }^{2,4,12}$. Nas situações em que a esplenectomia é inevitável, como em alguns tipos de trauma e doenças hematológicas, tem-se procurado preservar baços acessórios e realizar o implante de tecido esplênico ${ }^{1,2,3,7,9,13,14}$.

A viabilidade do tecido esplênico implantado é ainda um assunto controverso no tocante a sua capacidade e qualidade de regeneração e está na dependência do montante de tecido e local escolhido para sua implantação. Para avaliar a viabilidade do autotransplante de tecido esplênico realizou-se estudo experimental em ratos albinos, em cuja cavidade peritoneal e subcutânea foram implantados fragmentos de baço, com o objetivo de verificar sua regeneração sob o aspecto macroscópico, histológico e citológico.

\section{Métodos}

\section{Amostra}

Quarenta e quatro ratos albinos da linhagem Wistar, com idade de 80 dias e peso médio de $171 \mathrm{~g}$ foram distribuídos em 2 grupos:

Grupo A (n=22): receberam implante de tecido esplênico na tela subcutânea abdominal do entre a região do flanco e o hipocôndrio esquerdo, onde foram implantados um $(n=11)$ ou quatro fragmentos $(n=11)$ de baço, estes últimos distanciados $1 \mathrm{~cm}$ entre si.

Grupo B (n=22): receberam implantes de tecido esplênico na cavidade peritoneal, na região supramesocólica, na raiz do mesocólon transverso, onde se implantaram um $(n==11)$ ou quatro fragmentos de baço $(\mathrm{n}=11)$, estes últimos distanciados $1 \mathrm{~cm}$ entre si.

\section{Procedimento Operatório}

Os animais foram anestesiados por inalação com éter sulfúrico e submetidos à laparotomia mediana em condições assépticas. Identificado o baço, este foi retirado após a ligadura do pedículo, a $1 \mathrm{~cm}$ do hilo esplênico. O baço foi seccionado transversalmente em fatias de $1 \mathrm{~cm}$, com peso variando entre 180 e $200 \mathrm{mg}$ (Figura 1 ).

Os implantes foram colocados nos locais prédeterminados e o baço remanescente foi encaminhado para procedimento histológico a fim de ser utilizado como controle. A síntese da parede abdominal foi realizada com poliamida 5.0, em dois planos.

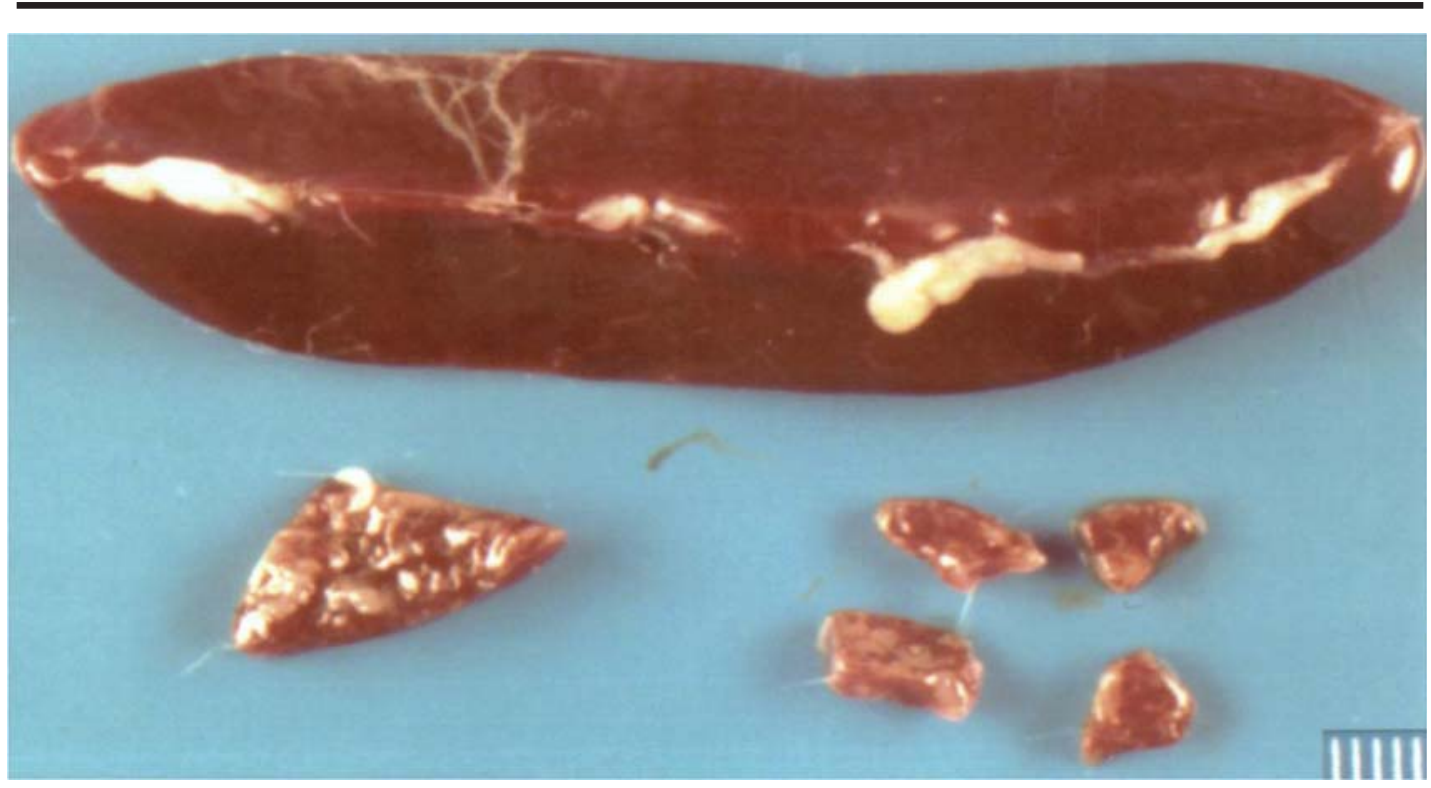

FIGURA 1- Aspecto macroscópico do baço íntegro e do tamanho dos fragmentos esplênicos (único e quatro) a serem implantados. 


\section{Coleta de Dados}

Após cinco semanas, os animais foram submetidos à eutanásia. Por meio de incisão xifopúbica, realizou-se a exploração dos compartimentos peritoneal e subcutâneo, à procura de tecido esplênico implantado. Os tecidos esplênicos implantados e eventualmente regenerados foram colhidos e encaminhados para processamento histológico. Os critérios de avaliação histológica foram: 1- análise da constituição dos elementos histológicos (população linfóide, áreas $\mathrm{T}$, áreas $\mathrm{B}$, trama reticulínica, vasos do parênquima esplênico e polpa vermelha ou seios venosos.) e comparadas com o baço normal (controle); 2- análise da reação entre a área receptora e os fragmentos implantados e regenerados, identificando-se a reação inflamatória periesplênica, a presença ou não de granuloma de corpo estranho, a fibrose parenquimatosa e a cápsula original (a presente parcialmente no tecido implantado) e/ou neoformada (cápsula formada após a regeneração do tecido

esplênico). Concomitantemente foi realizado o estudo citológico pelo esfregaço dos enxertos regenerados da cavidade peritoneal e da tela subcutânea. Após coloração pelo método de Leishmann, os seguintes elementos celulares foram analisados: células reticulares, linfóides, plasmócitos, neutrófilos, eosinófilos e monócitos.

\section{Estudo Estatístico}

Para verificar a regeneração esplênica (presença ou ausência) utilizou-se o teste exato de Fisher. Para as análises histológicas, utilizou-se o teste quiquadrado, mas, como ocorreram as restrições de Cochram, recorreu-se ao teste de Fisher. Para as análises citológicas fez-se uso do teste de Kruskall-Wallis, mas, em havendo diferenças significantes, complementou-se o processo com o teste de Mann-Whitney. O nível de significância estipulado foi de $5 \%(\mathrm{p}<0,05)$ para rejeição da hipótese de nulidade.

\section{Resultados}

TABELA 1 - Distribuição de tecido esplênico regenerado observado nos implantes da tela subcutânea e cavidade peritoneal, segundo a presença ou ausência e a porcentagem de sucesso do implante em se manter viável, independente do número de fragmentos.

\begin{tabular}{lccccc}
\hline Grupo & Presença & Ausência & Total & Proporção de sucesso (\%) & p $\geq 0,18$ \\
\hline Tela subcutânea & 21 & 1 & 22 & $95,4^{*}$ & $\mathrm{~ns}$ \\
Cavidade peritoneal & 18 & 4 & 22 & 81,8 & 88,6 \\
\hline Total & 39 & 5 & 44 & \\
\hline
\end{tabular}

$(p=0,182$, teste Exato de Fisher)

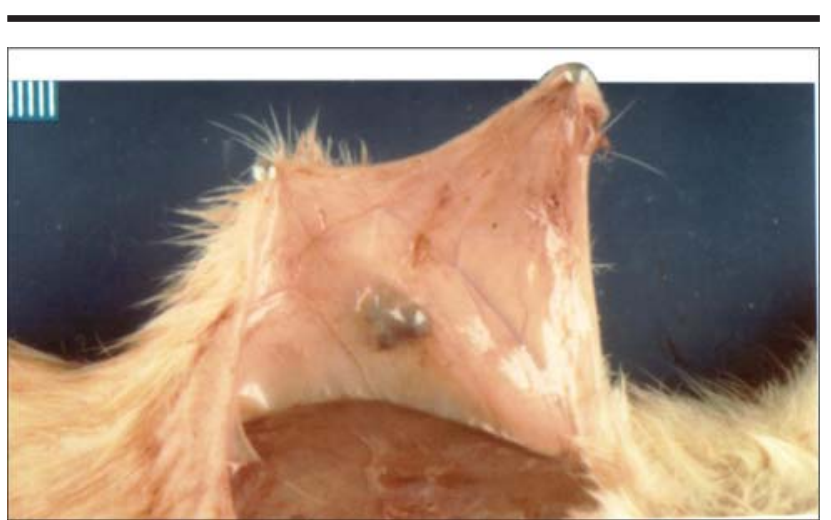

FIGURA 2 - Aspecto macroscópico da regeneração de quatro fragmentos de baçoimplantados na tela subcutânea.

Nos casos observados de migração do implante esplênico na cavidade peritoneal as regenerações ocorreram distantes do local implantado, como na grande e na pequena curvatura gástrica e no omento maior. Quando se compararam os elementos histológicos do tecido esplênico regenerado com o do baço normal, não se notou diferença estatística significante entre os grupos Ae B. Os resultados do estudo histológico que analisou a reação entre a área receptora e os fragmentos implantados e regenerados, não evidenciaram diferença estatística significante em relação aos grupos A e B. Os resultados do estudo citológicos em

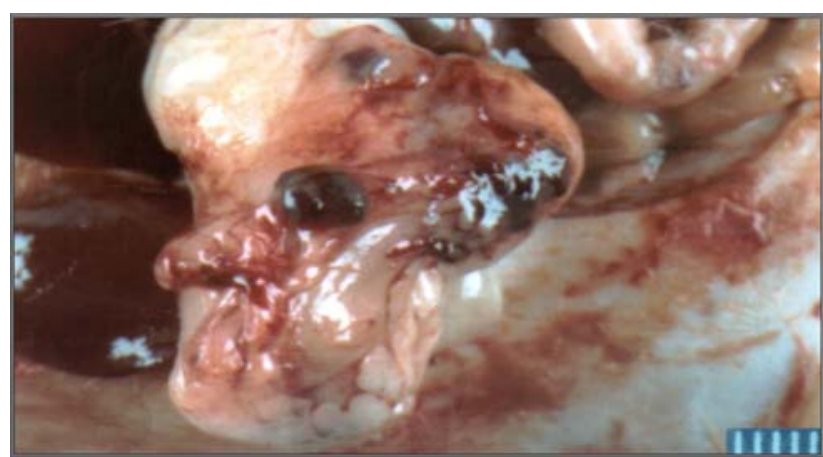

FIGURA 3 - Aspecto macroscópico da regeneração de um fragmento de baço implantado da cavidade peritoneal.

relação às células reticulares demonstraram que a média da cavidade peritoneal foi significativamente maior que a encontrada na tela subcutânea, porém não houve diferença significante em relação aos demais elementos citológicos estudados.

\section{Discussão}

A idéia de que a retirada do baço era isenta de complicações passou a ser contestada quando se demonstrou que essa víscera era indispensável ao 
desempenho de vários mecanismos de defesa do organismo “ como elaboração de IgM, de opsoninas, de gamaglobulina leucofítica, de tuftisina e de properdina e de filtração de microorganismos da corrente sangüínea. Observou-se que organismos asplênios apresentavam redução de linfócitos $\mathrm{T}$ circulantes, predisposição a alterações pulmonares 12,13,14,15,16 e maior risco de infecção por bactérias encapsuladas, como pneumococos e hemófilos ${ }^{1-12}$.

Esses fatos foram responsáveis pela conduta atual de conservar do baço sempre que possível. As opções para a preservação do tecido esplênico são variadas, como a esplenectomia parcial, a conservação de baços acessórios, o uso de colas hemostáticas e os tamponamentos.Quando nenhuma dessas condutas puder ser adotada, pode-se optar pela realização do autotransplante esplênico ${ }^{1,2,14,17}$.

$\mathrm{O}$ estudo realizado apresentou taxa de insucesso de $11,4 \%$, porém não mostrou diferença significativa da regeneração esplênica ou esplenose entre os fragmentos implantados tanto na tela subcutânea como na cavidade peritoneal. O estudo histológico e citológico, por sua vez, mostrou semelhança com o grupo controle em ambos os grupos. Rodrigues e col ${ }^{7}$ não encontraram diferenças na regeneração desses implantes nessas regiões: notaram apenas maior número de vasos neoformados nos tecidos regenerados do omento maior.

Pisters e col $^{3}$ preferem a cavidade peritoneal para realizar os implantes esplênicos, e a técnica que recomendam é envolvê-los no grande omento. Apesar de a esplenose poder ocorrer em localizações extraperitoneais ${ }^{3}$, alguns estudos experimentais têm dado preferência à cavidade peritoneal por acreditarem que a manutenção do suprimento sangüíneo é mais adequada, portanto com maior chance de regeneração e de estabelecimento de drenagem venosa com a circulação portal ${ }^{9,11,18}$. Estudos experimentais em animais em diferentes espécies e em humanos têm comprovado a grande capacidade de regeneração do tecido esplênico, além de apresentar semelhanças histológicas e citológicas com o baço ${ }^{1-9}$. Na espécie humana, quando se opta pelo implante esplênico, recomenda-se a utilização de 4 a 6 implantes de fragmentos de baço, com dimensões aproximadas de 40mm x 40mm x 3mm, alojados em bolsas confeccionadas no omento maior ${ }^{8}$. Os índices de sucesso da regeneração do fragmento de baço implantados têm relação direta com a sua superfície de contato e o sítio receptor. Por isso recomenda-se que os implantes devam ser seccionados no sentido transversal do maior eixo do baço ${ }^{1-11}$. A porcentagem de regeneração varia de 46 a $100 \%$ dos casos ${ }^{1}$.

O desenvolvimento do implante pode ser influenciado por alguns fatores: a presença do baço pode atuar como fator de inibição, já o organismo asplênico favorece o seu desenvolvimento ${ }^{11}$. Quando se realizam múltiplos implantes, o crescimento precoce de alguns deles pode prejudicar o desenvolvimento dos demais. Esse fato explica o fato de o número de implantes regenerados ser menor do que o inicialmente implantado ${ }^{1}$. Power e col ${ }^{18}$ encontraram maior desenvolvimento de tecido esplênico regenerado, utilizando-se o fator de crescimento vascular endotelial, como fator de estimulação. O presente estudo comparou o tecido do baço normal com esplenose, quer da tela subcutânea, quer da cavidade peritoneal, mostrou que não há diferença entre esses grupos. O estudo histológico que analisou a reação entre a área receptora e o tecido implantado “ que poderia atuar de forma desfavorável ao crescimento na regeneração do implante “ não evidenciou prejuízo em relação à regeneração esplênica tanto nos da tela subcutânea como naqueles da cavidade peritoneal. Observou-se menor espessamento da cápsula neoformada nas esplenoses da tela subcutânea. Esse achado pode ser explicado pelo fato de os implantes na cavidade peritoneal estarem mais sujeitos a aderências por estruturas como o omento, que resultam em uma cápsula neoformada mais espessada. Verificou-se que a irrigação do tecido regenerado se manteve de forma adequada mesmo nos casos em que se observou espessamento das cápsulas neoformadas. O estudo histológico da reação entre a área receptora e o implante (fibrose parenquimatosa, inflamação peri-esplênica, presença de granuloma de corpo estranho e cápsulas fibrosadas) mostrou que a presença de dois desses fatores tinha como conseqüência hipodesenvolvimento dos tecidos linfóides (população linfóide, áreas T e B).

O estudo citológico mostrou que as células reticulares (responsáveis pela regeneração ad integrum do tecido implantado) eram mais numerosas no grupo que recebeu implante na cavidade peritoneal. Apesar desse resultado, não se notou prejuízo ao desenvolvimento dos enxertos do subcutâneo. As análises citológicas das demais células estudadas não mostraram diferença significativa em relação aos implantes realizados na tela subcutânea ou na cavidade peritoneal.

\section{Conclusão}

A regeneração do tecido esplênico heterotópico e autólogo em ratos é viável tanto na cavidade peritoneal como na tela subcutânea, ocorre de maneira equivalente, com alta incidência de regeneração e com aspectos histológicos e citológicos semelhantes aos do baço normal.

\section{Referências}

1. Souza JCL. Estudo da regeneração esplênica autóloga e heterotópica em ratos. Tese - Faculdade de Ciências Médicas da Santa Casa de São Paulo, 1982. 95p.

2. Esposito TJ, Gamelli RL. Injury to the spleen. In Mattox KR, Feliciano DU, Moore EE. Trauma. 4 ed. New York: International Edition. 2000; cap 31, p683-710.

3. Pister PWT, Pachter. Autologous splenic transplantation. Ann Surg. 1994;219 (3):225-35.

4. Zúñiga CT, Molina HZ, Alvarez RU, Seguel ES, Benavides CY, Arostegui CP et al. Traumatismo esplénico, experiencia en el manejo quirúrgico. Rev Chil Cir. 2002;54 (1):79-84.

5. Krivit W, Giebink GS, Leonard A. Overwhelming postsplenectomy. Surg Clin North Am. 1979;9(2):223-33.

6. King H; Shumacker Junior, HB. Splenic studies. I Susceptibility to infection after splenectomy performed in infancy. Ann Surg. 1952;135 (2):239-42.

7. Rodrigues, AZ, Nigro AJT, Paiva ER, Sementilli A, Tavares NM. Estudo comparativo da viabilidade de fragmento de tecido esplênico implantado no omento maior ou na tela subcutânea em ratas. Acta Cir Bras. 1991;6 (2):64-7.

8. Nunes CCA, Nunes WV, Waechter FL, Pereira Lima L. 
Trauma esplênico. Valor do autotransplante. Rev Med Sta Casa, Porto Alegre. 1994;5 (10):1038-44.

9. Brandt CT, Maciel DT, Frei Caneca AO, Castro CMB, Araújo LB. Autotransplant of spleen tissue in children with schistosomiasis: evaluation of splenic function after splenosis Mem. Inst Oswaldo Cruz, 2001;98:117-22.

10. Petroianu A. Cirurgia conservadora do baço. In Petroianu A. Terapêutica cirúrgica: indicações, decisões, tática, técnica. Rio de Janeiro: Guanabara Koogan, 2001; cap 43, p.401-20.

11. Heil RI, Malafaia O, Matias JEF, Ribas Filho JM, Campos ACL, Mello LR, Simões JC. Viabilidade histológica do autotransplante esplênico em omento maior, retroperitôneo, mesentério e tecido subcutâneo de cães submetidos a esplenectomia total. Arq Bras Cir Dig. 2001;14(4):174-77.

12. Resende V, Petroianu A. Funções do remanescente esplênico após esplenectomia subtotal para o tratamento de lesões complexas do baço humano. Rev Assoc Med Bras. 2002;48(1):26-31.

13. Petroianu A. Auto-implante esplênico. In Petroianu A. Terapêutica cirúrgica: indicações, decisões, tática, técnica. Rio de Janeiro: Guanabara Koogan, 2001; cap 44, p. 421-7.
14. Marques RG, Petroianu A, Coelho JM, Portela MC. Regeneration of splenic autotransplants. Ann Hematol. 2002;8(6):622-6.

15. Sandoval OO, Curbelo ONM, Borges FFB. Cirurgia conservadora de la función esplénica en el adulto joven. Rev Cubana Cir. 1995;34(2): 1-3.

16. Leemans R, Harms G, Rijkers GT, Timens W. Spleen autotransplantation provides restoration of functional splenic lymphoid compartments and improves the humoral immune response to pneumococcal polysaccharide vaccine. Clin Exp Immunol. 1999;117(1):5996-604.

17. Mantovani M, Fontelle S, Fraga GP, Meirelles GV. Trauma abdominal fechado. Tratamento não-operatório das lesões esplênicas. Rev Para Med. 2002;16 (2):46-51.

18. Power RE, Kay EM, Bauchier-Hayes D. Exogenous and endogenous angiogenic stimuli do not augment splenic autotransplantation. Eur J Surg. 2002;168(4):247-50.

\section{Agradecimentos}

Agradecemos ao Prof. Jefferson Rosa Cordeiro pela revisão da análise estatística.

\section{Correspondência:}

Dr. José Carlos Lacerda de Souza

Av. Bandeirantes, 500/sala 103

86010-010 Londrina - PR

Tel/Fax: (43)3324-4067

jclsouza@londrina.net
Conflito de interesse: nenhum

Fonte de financiamento: nenhuma

Recebimento: 14/01/2005

Revisão: 16/02/2005

Aprovação: 17/03/2005

\section{Como citar este artigo:}

Souza JCL, Athiê E, Marigo C, Rahal F, Fagundes DJ. Estudo da regeneração esplênica autóloga e heterotópica em ratos. Acta Cir Bras. [periódico na Internet] 2005 Maio-Jun;20(3). Disponível em URL: http://www.scielo.br/acb

*Figuras coloridas disponíveis em $\underline{\text { http://www.scielo.br/acb }}$ 